\title{
Fine Structure of the Sense Organs on the Labella and Labium of the Mosquito Aedes aegypti (L.)
}

\author{
R.M.K.W. Lee ${ }^{*}, 1$ and D.A. Craig ${ }^{2}$ \\ ${ }^{I}$ Department of Anesthesia, McMaster University, Hamilton, Ontario, L8N 3Z5, Canada \\ ${ }^{2}$ Department of Biological Sciences, University of Alberta, Edmonton, Alberta, T6G $2 E 9$
}

\begin{abstract}
Fine structure of the sense organs on the labella and labium of male and female mosquito Aedes aegypti is described. Labellar hair on the outside of the two labellar lobes are consisted of long mechanoreceptive hairs, medium-sized chemoreceptive hairs containing 3-5 dendrites, and short papillae which are probably olfactory receptors. Two apical hairs each containing five dendrites not reported before are found deeply embedded inside each labellum. They emerged between folds at the tip of the labellum. These and other sensory hairs on the outside of the labella are probably involved in finding a suitable place for feeding after a mosquito has landed on a host. Six anteriorly directed papillae each containing 3-5 dendrites are found on the oral surface of each labellar lobe with no evidence of mechanoreceptors associated with these papillae. These papilla are probably chemosensory and are involved in detecting the food entering the food canal when a mosquito feed on water and other liquid diet such as nectar. A chordotonal organ with two sensory cells is found inside each labellum, and this organ has not been described on mosquito mouthparts before. These chordotonal organs probably function to monitor the spreading and closing of the labellar lobes during feeding. Mosquito spread their labellar lobes when feeding on water and sugar but these lobes are firmly pressed against each other when they feed on blood. Ligular hairs are definitely not sensory because of a lack any dendrites inside these hairs. Labial hairs proximal to the labella are probably mechanoreceptors because only one nerve cell is associated with each hair with nerve terminating at the base of the hair. Based on results from behavioral and functional studies, the function of these sensilla during feeding is described.
\end{abstract}

Keywords: Mosquito, mouthparts, sensilla, labellum, labium, sense organs, feeding.

\section{INTRODUCTION}

Because of the medical and economic importance of mosquitoes, the study of the sense organs and feeding behavior of mosquitoes has attracted the attention of many researchers. Gustatory discrimination after the mosquito has landed on a host may be a function of the tarsal hairs. Tarsal chemosensory hairs have been reported in different species of mosquitoes [1-6]. In probing to find a suitable spot for feeding, the mosquito uses the two labellar lobes located at the tip of the long, gutter-like labium [7-9]. The structure of the labellar sense organs in mosquitoes has been studied using light microscopy (LM) $[1-4,10,11]$, scanning electron microscopy (SEM) [12], and transmission electron microscopy (TEM) [5, 13-15]. The limitation of these studies was that only some sense organs were studied, i.e. they were not comprehensive. Behavioral [1-4, 14-18] and electrophysiological studies $[5,12,15,19]$ were carried out to elucidate the function of the labellar hairs. However, functional studies of the labellar hairs were conducted mostly on limited types of hair. A thorough knowledge of the distribution and fine structure of the labellar sense organs is still lacking.

In this study, the structure of the sense organs on the labium of both sexes of Aedes aegypti (L.) was studied using

*Address correspondence to this author at the Department of Anesthesia (HSC-2E3), McMaster University, 1200 Main Street West, Hamilton, Ontario, L8N 3Z5, Canada; Tel: (905) 521-2100 x75177; Fax: (905) 523-1224; E-mail: rmkwlee@mcmaster.ca
LM, SEM and TEM. These observations are integrated into the present body of knowledge on the sense organs on the mouthparts of mosquitoes in relation to their feeding behavior.

\section{MATERIALS AND METHODS}

A culture of A. aegypti was maintained in the insectary at $27^{\circ} \mathrm{C}$ and $65 \%$ R.H. with eggs kindly donated by Dr. A. S. West (Department of Biology, Queen's University, Kingston, Ontario, Canada). For LM, heads from newly emerged mosquitoes were preserved in alcoholic Bouin for 48 hours or more, double-embedded in $2 \%$ celloidin and paraplast, sectioned at $5 \mu \mathrm{m}$, stained with Gomori's trichrome, and mounted in DPX. Burgess and Remple's [20] method for vital methylene blue staining was used to observe innervation of the sensilla. Sections and whole mounts of the labella and labium were examined by conventional and phase contrast microscopy.

For SEM, heads of 1-3-day-old adult mosquitoes were fixed in 5\% Formalin. The tip of the labium with the labella was removed from the head using a fine needle. The specimens were dehydrated through a graded series of ethanol, cleared in xylene, air-dried on a glass slide, coated with carbon and gold, and observed with a Cambridge Stereoscan S4 scanning electron microscope.

For TEM, newly emerged mosquitoes were anesthetized with chloroform. The tip of the labium with the labella was removed and fixed in 3\% glutaraldehyde and 1\% osmium 
tetroxide, following the procedure of Hooper et al. [21]. Specimens were embedded in Araldite or Spurr's low viscosity resin. Sections were cut on a Reichert Om-U2 ultramicrotome, mounted on single-hole grids supported with carboncoated Formar film, stained with uranyl acetate and lead citrate, and examined in a Philips EM 300 electron microscope.

\section{RESULTS}

The following description applies to both sexes of $A$. aegypti as the distribution and the structure of the labellar and labial sense organs are similar in both sexes.

The two labellar lobes at the tip of the labium together form a pear-shaped structure (Figs. 1, 3). Each labellum is two segmented. The two segments abut obliquely to each other on the dorsal surface (Fig. 1), and horizontally on the ventral surface (Fig. 3). A ligula covered with hairs projects out between the two labellar lobes (Fig. 5), and contains the

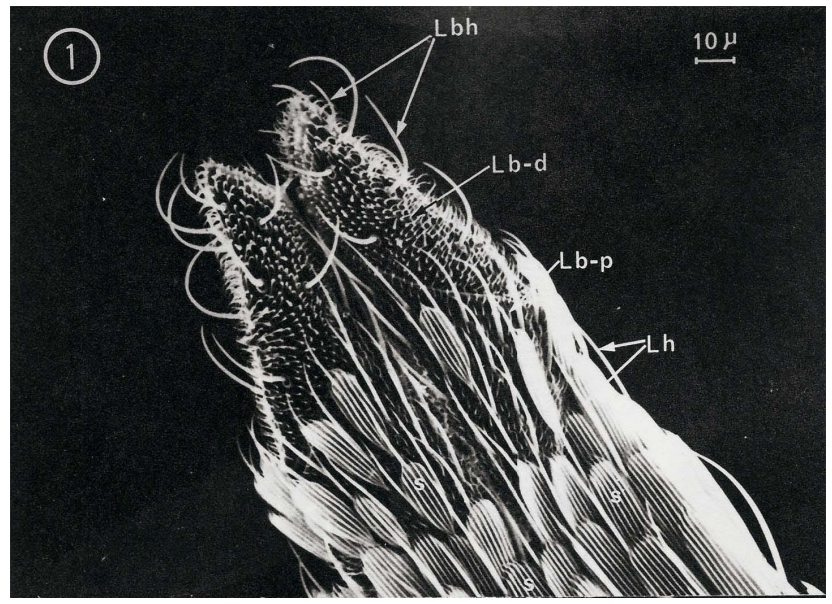

Fig. (1). Dorsal aspect of female A. aegypti showing labellar (Lbh) and labial (Lh) hairs. Each labellum is composed of a distal (Lb-d) and a proximal (Lb-p) segment. Scales (s) are found on the proximal labellar segment.

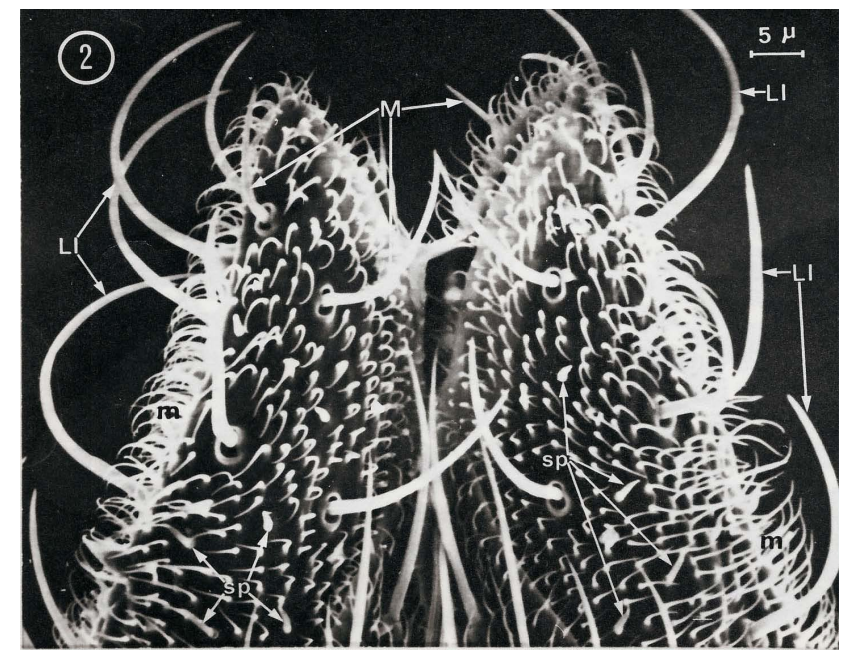

Fig. (2). Same at high magnification showing different types of labellar hairs. L1, long labellar hairs; M, medium-sized hairs; m, microtrichia; sp, short papillae. The short papillae are also socketed at the base.

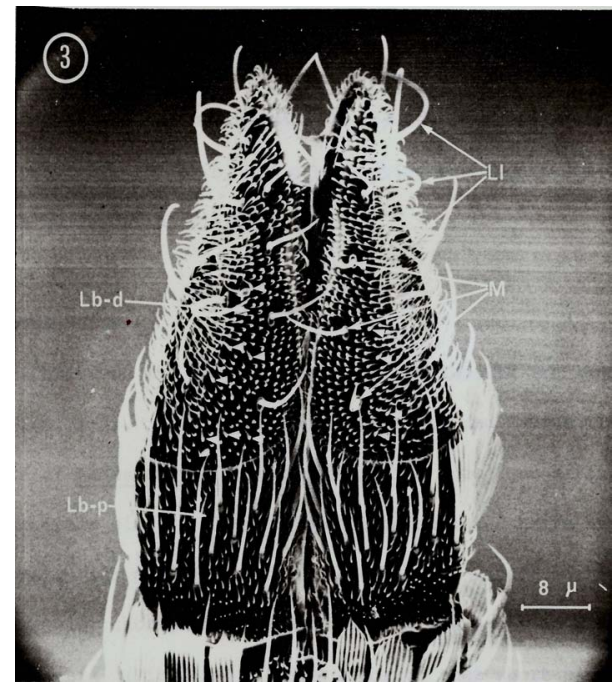

Fig. (3). Ventral aspect of female A. aegypti labella, showing the distal (Lb-d) and proximal (Lb-p) segments of the labella are joined transversely. Long labellar hairs (L1), medium-sized hairs (M), and short papillae (arrowheads) are also found here. Note scales are almost absent on the proximal labellar segment.

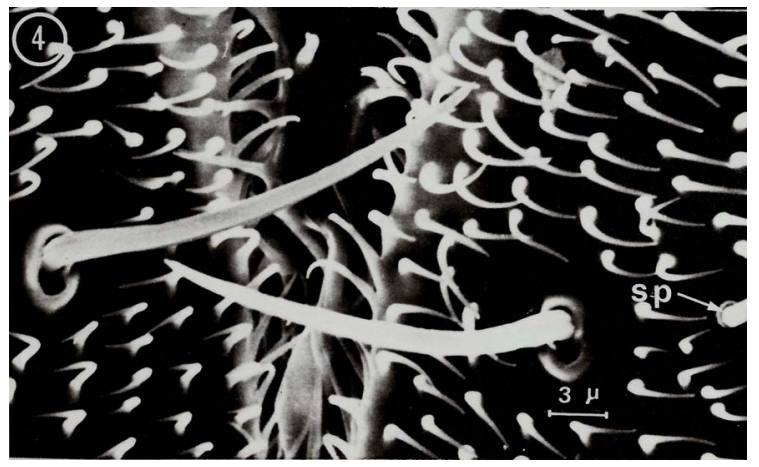

Fig. (4). Same at higher magnification showing hair socket at the base of a short papilla (sp).

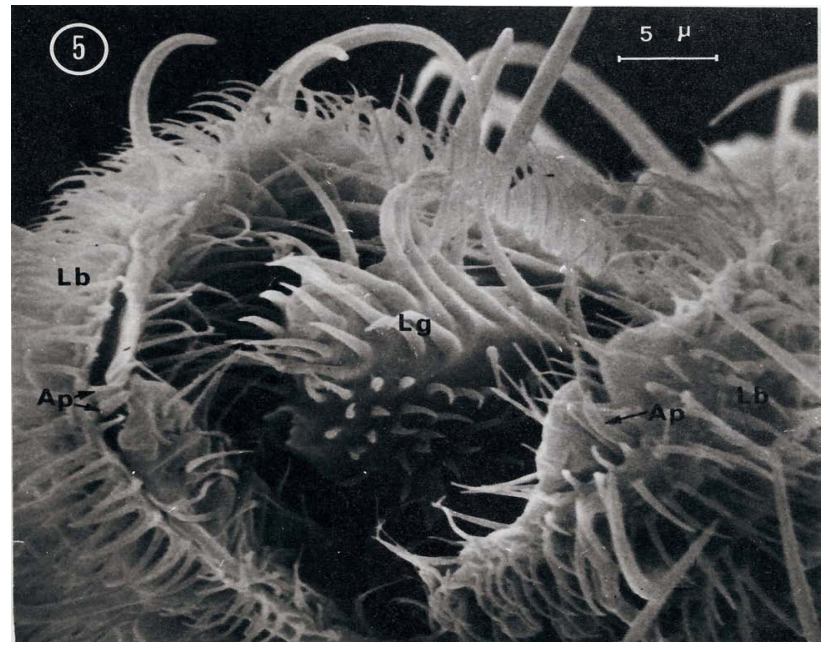

Fig. (5). Anterior top aspect of the tip of female A. aegypti labium, showing ligula $(\mathrm{Lg})$ situated between the two labellar lobes (Lb). Ligular hairs are not socketed at the base, and have smooth wall. Two apical hairs (Ap) extend out anteriorly through labellar folds at the tip. 
tip of the fascicle on its trough-shaped dorsal surface. As the concave inner surfaces of the labella are facing the labral food canal, we will refer to the inner surface of the labellum as the oral surface, and the outer convex surface of the labellum as the aboral surface.

\section{Aboral Hairs}

Aboral hairs on the distal segment of the labella are symmetrically arranged (Figs. 1-4). As noted by Frings and Hamrum [2], aboral hairs of A. aegypti can be classified into four different types according to their sizes: (1) long, pointed, socketed hairs averaging $40 \mu \mathrm{m}$ in length, (2) medium-sized, socketed, blunt-tipped hairs between 20-30 $\mu \mathrm{m}$ long, (3) short, blunt, socketed papillae 4-6 $\mu \mathrm{m}$ long and (4) short microtrichia (Figs. 1-4). They reported that short papillae are present only on the dorsal surface of the labella. However, we found that these papillae are also present on the ventral surface (Figs. 3, 4). Hairs on the proximal segment of the labellar lobes are all straight, socketed and have fine tips (Figs. 1, 3, 6).

\section{Long Labellar Hairs}

Longitudinal ridges are found on the hair shaft of the long labellar hairs, but only a single cavity is found inside the hair lumen (Figs. 6-9). Each longitudinal ridge is finely scalloped on its surface (Figs. 7, 8). A finely granulated substance is present inside the hair lumen. There is no evidence of any dendrites inside the lumen. Near the tip of the hair shaft, the lumen becomes smaller (Fig. 7), and it is very likely that these hairs do not have any opening to the outside. Crystal violet [22] did not stain the tips of these hairs indicating no opening at the tip. Structurally, these hairs are very similar to the thick-walled hairs found on the antennal flagel-
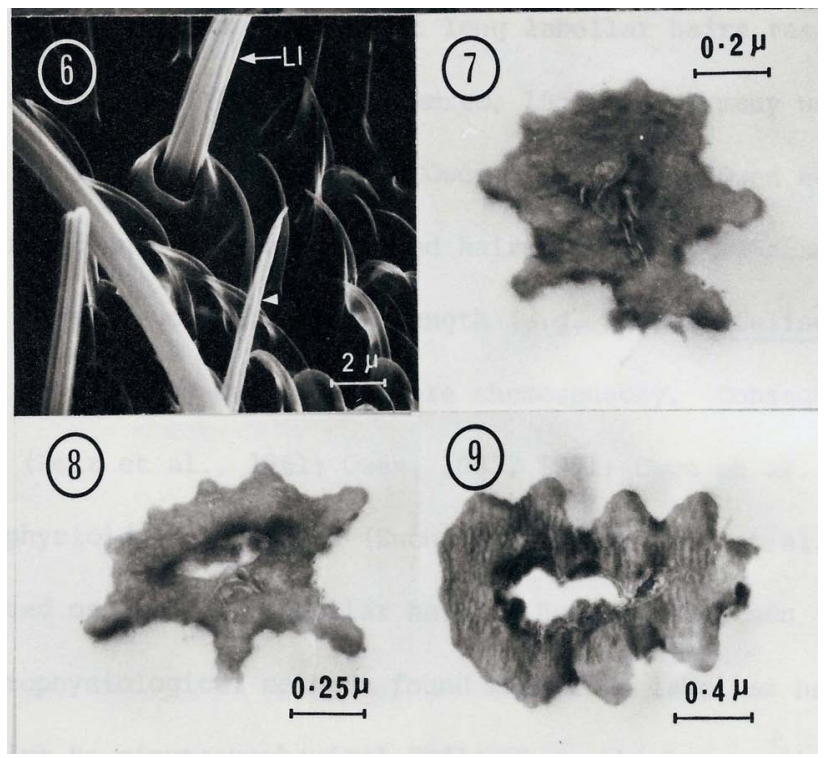

Fig. (6). Long labellar hair (Ll) of male A. aegypti showing longitudinal ridges on the hair, and sharp pointed tip (arrowhead) of labial hair.

Figs. (7-9). Transverse sections of long labellar hairs of female $A$. aegypti Near the tip (Fig. 7), longitudinal ridges appear as points of a star. Proximal to the tip (Fig. 8) and near the base (Fig. 9), a single lumen appeared. Note the absence of dendrites inside the lumen. lum of A. aegypti described by Slifer and Sekhon [23]. A mechanoreceptive dendrite is found at the base of the long labellar hairs (Fig. 10). Whether this dendrite is attached to the hair base, or enters into the hair lumen for a short distance is unclear.

\section{Medium-Sized Hairs}

These hairs are situated near the tip and on the dorsal and ventral aspects of the aboral surfaces of the labellar lobes. They are longitudinally grooved on the outside, and doublechambered inside. Three to five dendrites are present in one of the two chambers (Figs. 11-13). In some hairs containing three dendrites, three to four other dark, dendrite-like structures can be seen (Fig. 12).

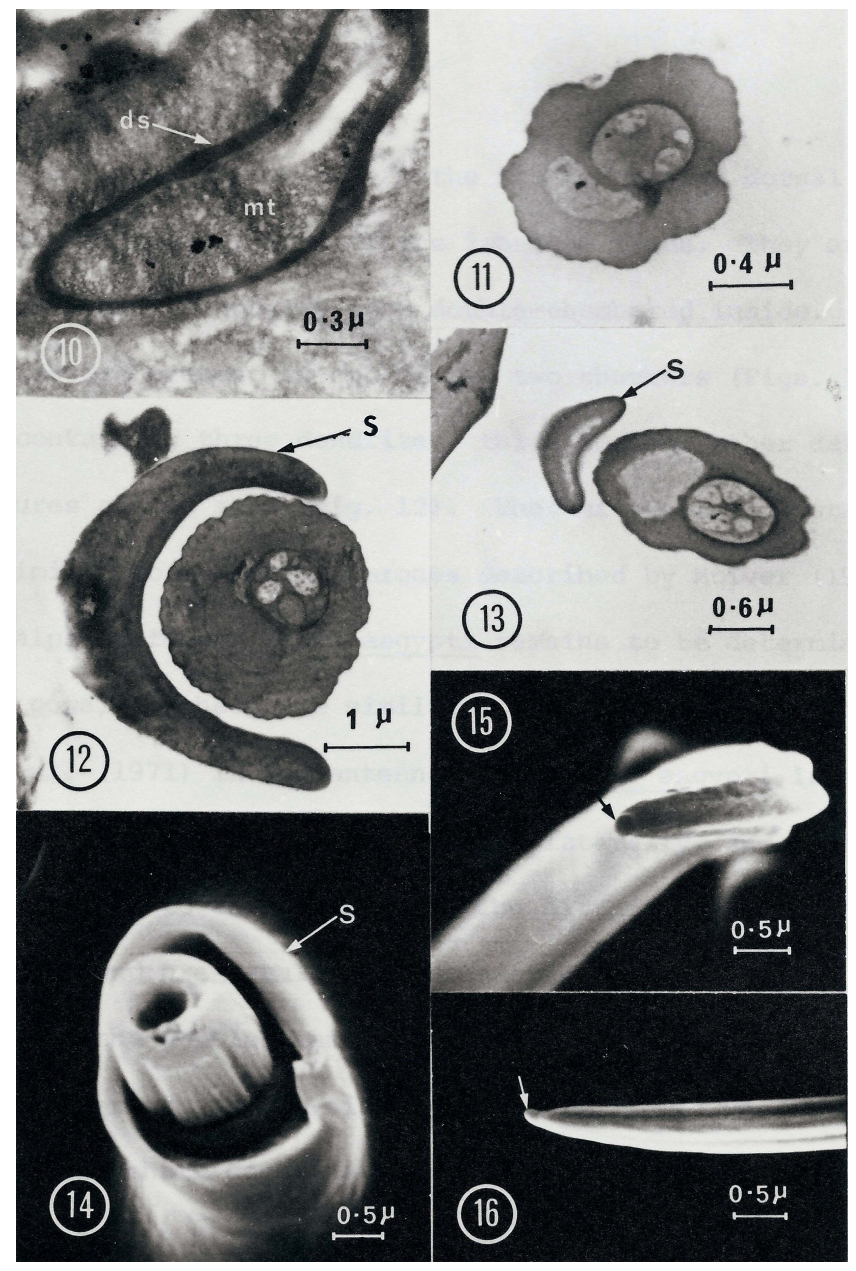

Fig. (10). Section near the base of a long labellar hair of female $A$. aegypti showing microtubules $(\mathrm{mt})$ of the mechanoreceptive dendrite enclosed by a dendritic sheath (ds).

Figs. (11-13). Transverse sections of medium-sized labellar hairs of female A. aegypti. Each hair is double-chambered, with one chamber containing dendrites and the other a liquid with fine granules. Three to five dendrites are found in the circular chamber. S, hair socket.

Fig. (14). A medium-sized labellar hair broken near the base of a male A. aegypti labellum showing longitudinal ridges on the hair shaft and two chambers inside the hair shaft. S, hair socket.

Figs. (15 and 16). Medium-sized labellar hairs of a female $A$. aegypti showing a drop of an unknown substance at the tip of the hair. 
With SEM, the double-chambered structure of the hair shaft can also be seen in broken medium-sized hairs (Fig. 14). The dendrite-free lumen of the hair shaft contains remnants of the trichogen cell. A substance is found at the tip of some medium-sized hairs (Figs. 15, 16), which might be similar to the viscous droplets reported on the labellar and tarsal hairs of blowfly and stablefly [24, 25]. It is possible that this fluid is secreted through the dentrite-free chamber of the hair shaft.

At the base of the medium-sized hairs, three to five dendrites are found inside the dendritic sheath (Figs. 17-21). The dendritic sheath is surrounded by the trichogen cell, the latter in turn is enveloped by the tormogen cell (Figs. 17, 19, 21). Septate-desmosomes are found at the junction of the two enveloping cells (Fig. 17). At the ciliary region of one dendrite, it appears that there are $9+1$ microtubular doublets (Fig. 18), instead of the usual $9+0$ configuration generally found in insect chemoreceptors [26]. However, because some doublets at the periphery of the dendrite are not as distinct as the central one, it is difficult to interpret the micrograph with certainty. It is possible that this was due to the branching of the microtubules, and that one of the doublets was displaced into the center. Vesicles are found in between the dendrites, and microtubules are present in the extension of the trichogen cell that encloses the dendritic sheath (Fig. 18). Good fixation for mosquito labellar hairs is difficult to obtain. Similar difficulty was also encountered by Stürckow et al. [25] in studying the labellar hairs of the blowflies.

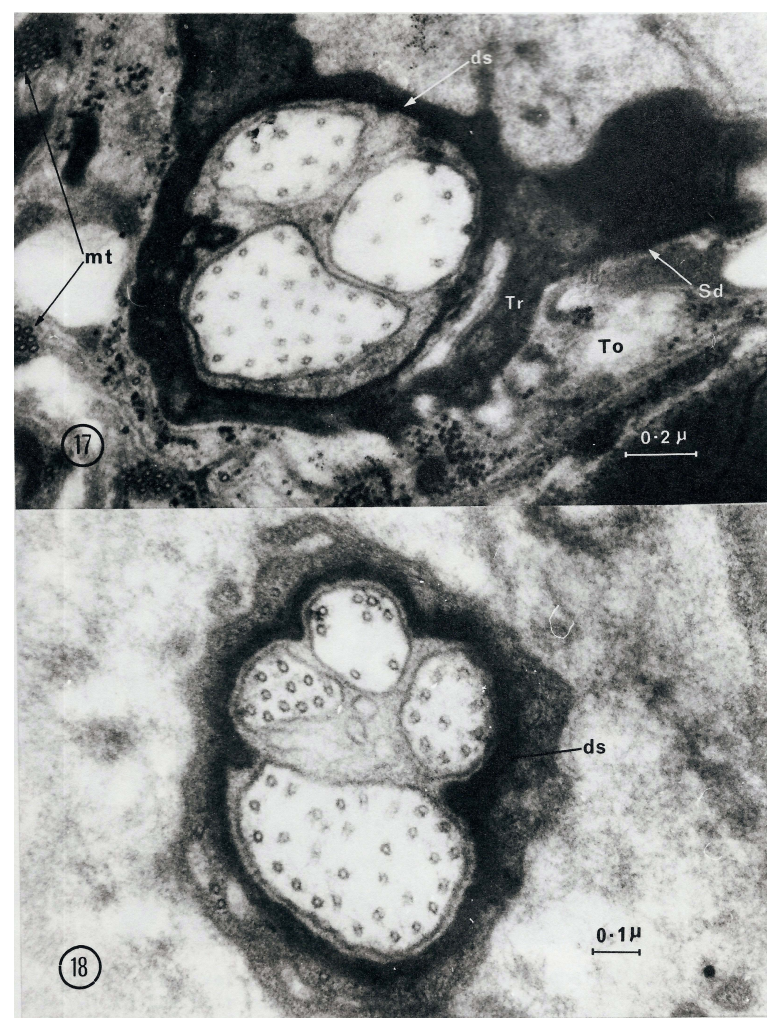

Figs. (17 and 18). Transverse section of medium-sized labellar hair sensilla proximal to the hair showing sensilla with three (Fig. 17) and four (Fig. 18) dendrites enclosed by a dendritic sheath (ds). Microtubules (mt) are found inside the trichogen cell (Tr) which enclosed the dendritic sheath and outer tormogen cell (To). Septate desmosomes ( $\mathrm{Sd})$ are found where these two cells come into contact.

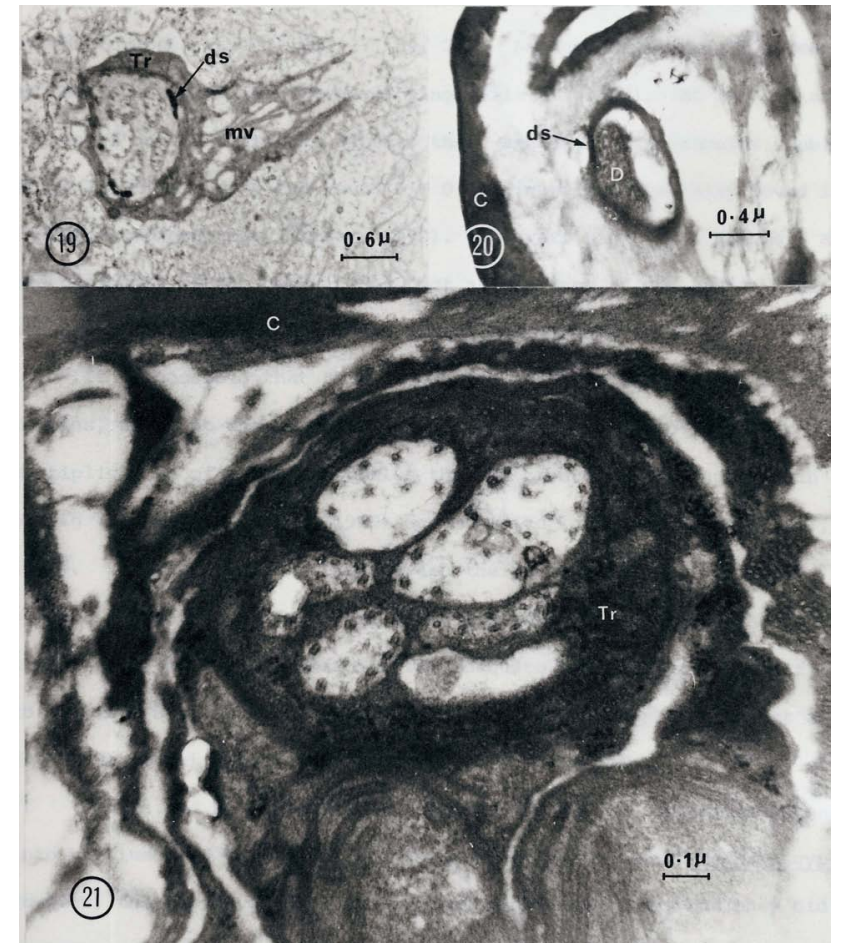

Figs. (19-21). Transverse section of medium-sized labellar hair sensilla proximal to the hair base with five dendrites. Inside the labellum proximal to the hair socket, dendritic sheath (ds) surrounding the dendrites almost disappeared here (Fig. 19) and microvilli $(\mathrm{mv})$ are found on one side of the trichogen cell (Tr). A mechanoreceptive dendrite (D) enclosed by a dendritic sheath (ds) is present at the base of the hair (Fig. 20). Microtubular doublets are found in some dendrites (Fig. 21). C, surface cuticle.

\section{Oral Papillae}

Six anteriorly directed, socketed papillae are found on the concave, oral surface of each labellar lobe (Fig. 22). On the dorsal and ventral oral surfaces, pseudotrachea-like structures are found, and oral papillae are sometimes found in between the microtrichia (Fig. 23). An opening approximately $0.15 \mu \mathrm{m}$ in diameter is found at the tip of the papilla (Fig. 24). Vital methylene blue staining of the labella showed that these papillae have dendrites entering the lumen which extend to the tip (Fig. 25). TEM sections show that the papillae are double-chambered, with three to five dendrites inside the big chamber. The dendrites are enclosed in a dendritic sheath (Figs. 26-28). Proximal to the base of the papillae, three to five dendrites are enclosed in a dendritic sheath, the latter enveloped by the trichogen and tormogen cells (Figs. 29, 30). We found no evidence of mechanoreceptive dendrite terminating near the base of the papillae. Septate-desmosomes are found between the junction of the trichogen and tormogen cells (Fig. 29).

\section{Chordotonal Organ}

Inside each labellum, a chordotonal organ with two sensory cells associated with it is situated close to the oral papillae (Figs. 30, 31). At the ciliary region of the sensory cells, the cells are surrounded by six scolopale rods (Fig. 31). Desmosomes are found between the cell membrane of the 


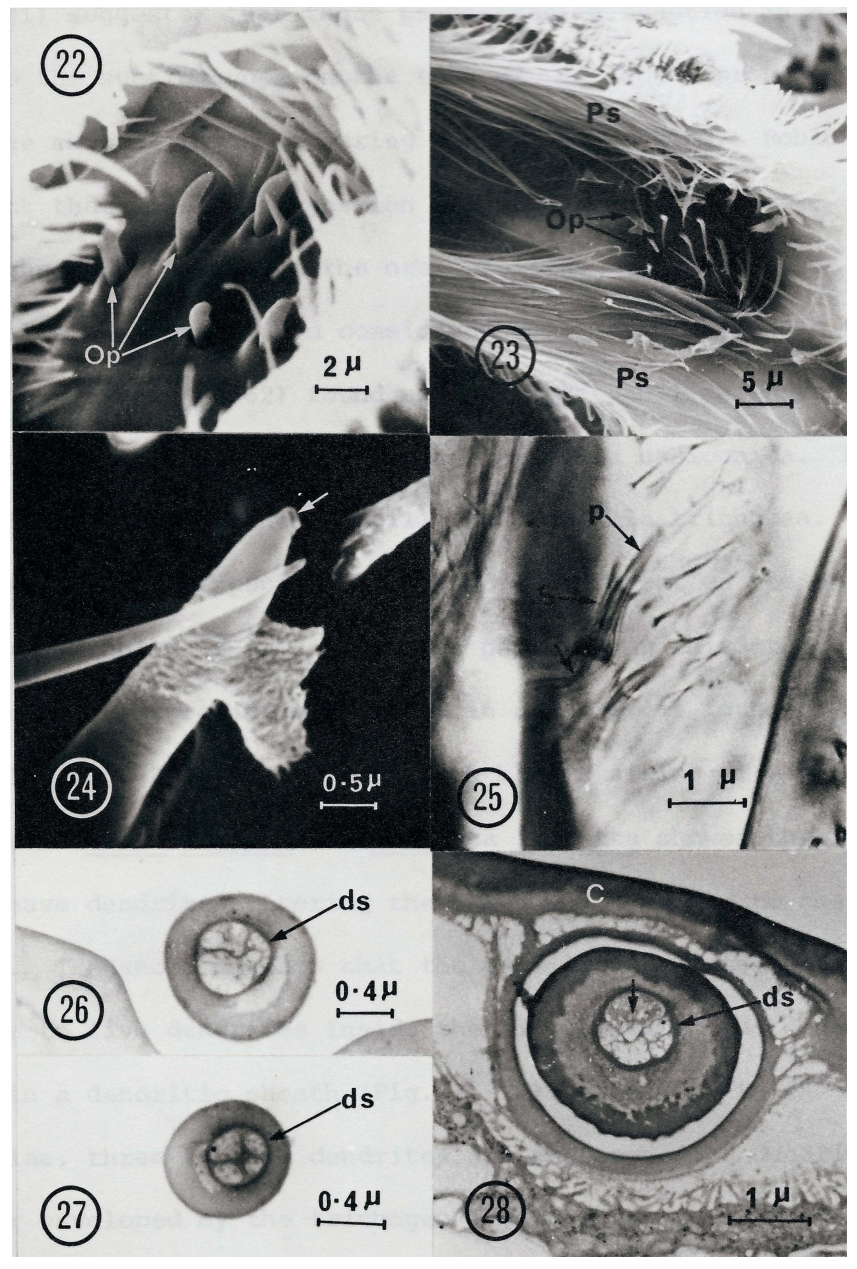

Fig. (22). Oral papillae (Op) on the oral surface of female A. aegypti labellum. Note the smooth surface of the papilla.

Fig. (23). Oral papillae (Op), and pseutrachea-like structure (Ps) on the two lateral oral surfaces of a labellum from a male $A$. aegypti.

Fig. (24). Higher magnification of Fig. 23 showing an opening (arrow) at the tip of an oral papilla.

Fig. (25). Vital methylene blue staining of a female Culiseta inornata labellum, showing dendrites entering through hair socket (S) into the lumen of an oral papilla (p). The dendrites are constricted just below the socket (arrow), where the ciliary region of the dendrites is probably located.

Figs. (26-28). Transverse sections of oral papilla showing 3-5 dendrites inside a dendritic sheath (ds). One dendrite near the base (arrow, Fig. 28) is bigger than the others, probably a mechanoreceptive dendrite. $\mathrm{C}$, surface cuticle.

sensory cells, and also between the sensory cell membrane and scolopale rods (Fig. 31). At the distal end of the chordotonal organ, only a single cap is present, which is surrounded by concentric layers of fibrous elements (Fig. 30). We were unable to determine the distal attachment of the chordotonal organ using TEM, because of a lack of serial sections. From LM sections, it seems that the cap is attached to the oral surface, at a region slightly anterior to the oral papillae.

\section{Apical Hairs}

Inside each labellum, there are usually two hairs deeply embedded in the lobe. Three apical hairs are found in some

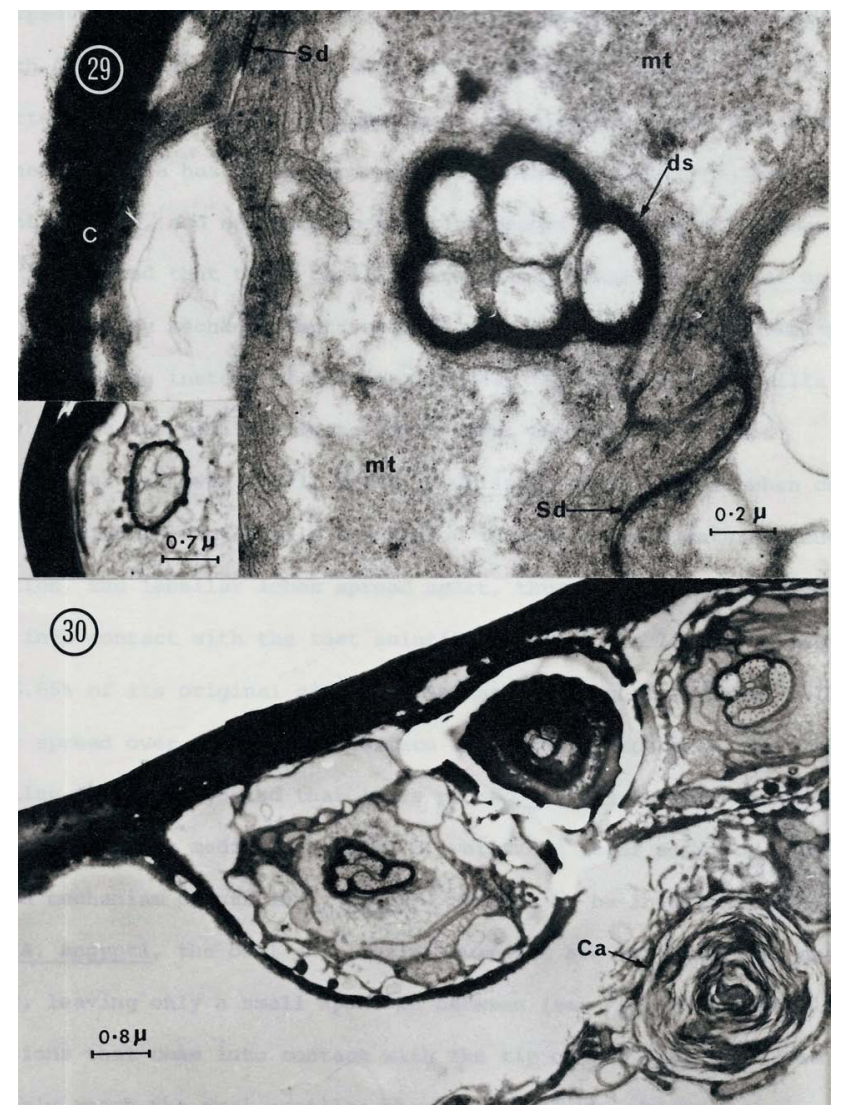

Fig. (29). Transverse section of an oral papilla sensillum proximal to the base in a female A. aegypti showing five dendrites. Microtubules are found in the trichogen cell surrounding the dendritic sheath (ds). Septate Desmosomes (Sd) are found at the junction between the trichogen and tormogen cells. C, surface cuticle; mt, microtubules. Inset shows one sensillum with three dendrites.

Fig. (30). Section of a labellum showing three oral papillae with three to five dendrites, and the cap $(\mathrm{Ca})$ of a labellar chordotonal organ.

specimens. These hairs emerge anteriorly through longitudinal "tubes", and project out between the folds at the tip of the labellum (Fig. 5). Near the distal end of the labellum, the two hairs share a common "tube" for a short distance (Fig. 34), but proximally, each hair is enclosed by a separate "tube" (Fig. 35). Vital methylene blue staining showed that these hairs are socketed at the base, with dendrites entering the hair lumen and extending to the tip of the hairs (Fig. 32). TEM sections of these hairs showed that these hairs are double-chambered, with the smaller chamber containing five dendrites (Fig. 33). Near the base of the hair besides the two lumina found at the distal end of the hair shaft, a third lumen appears (Fig. 35). This third lumen is probably the trichogen cell sinus. The dendritic sheath surrounding the dendrites becomes very distinct at this region. Proximal to the hair base, the dendritic sheath is enveloped by trichogen and tormogen cells, and the trichogen cell encloses the trichogen cell sinus (Fig. 36). The axons of these dendrites later join the labial nerve. As the number of dendrites at the hair tip is the same as that proximal to the hair base, and we could not find any evidence of a dendrite ending near the hair base, it is possible these apical hairs do not have a mechanoreceptive 


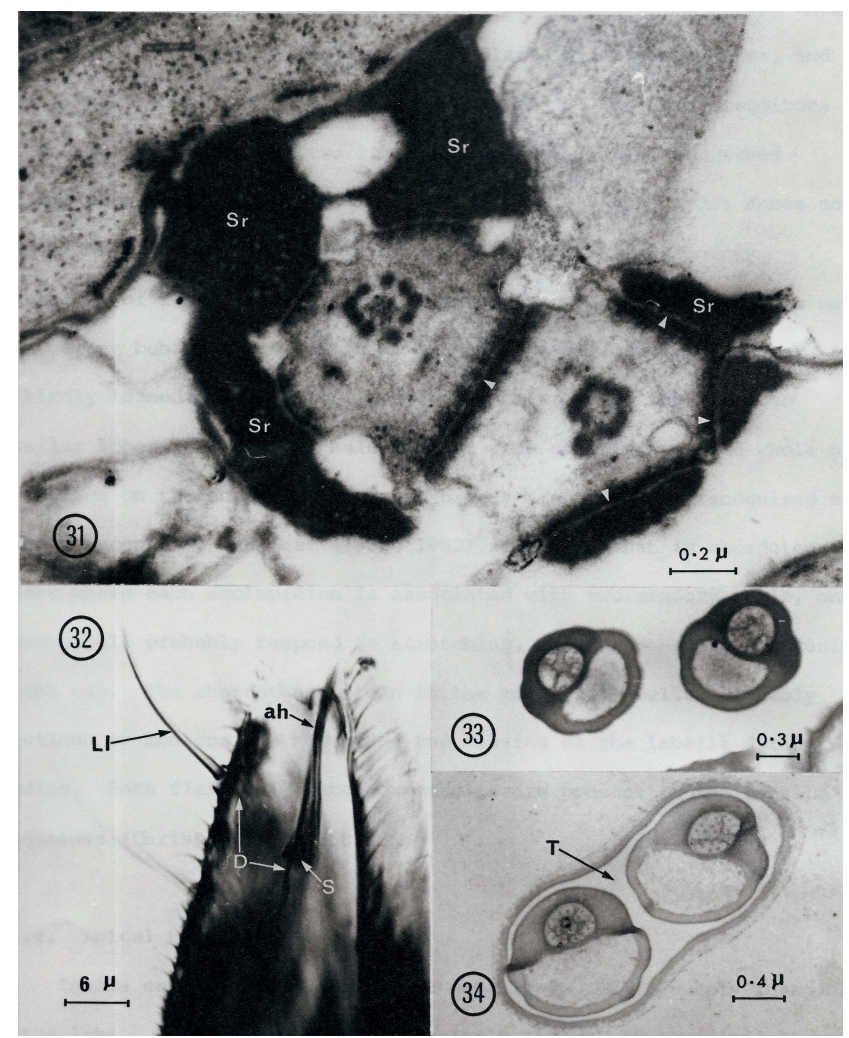

Fig. (31). Transverse section of a labellar chordotonal organ showing electron-dense scolopale rods ( $\mathrm{Sr}$ ) surrounding two sensory neurones. Desmosomes (arrowheads) are found at the junction between the two sensory neurones, and also between the scolopale rods and sensory neurones.

Fig. (32). Vital methylene blue staining showing dendrites (D) leading to the base of a long labellar hair (Ll) and an apical hair (ah). S, socket.

Figs. (33 and 34). Transverse section of two apical hairs near the hair tip (Fig. 33) of a labellum and inside the labellum (Fig. 34), showing 4-5 dendrites inside the smaller round chamber. $\mathrm{T}$, a common tubular channel shared by the two sensory hairs.

dendrite ending near the base of the hair. Not all the five dendrites found in the hair shaft extend to the tip of the hair. In some sections at the distal end of the hair, only four dendrites are found (Fig. 34).

\section{Ligular Hairs}

Cuticular hair-like projections covering the ligula in $A$. aegypti are not socketed at the base (Fig. 5). Each projection has a single lumen inside, but is devoid of any sensory structure. Transverse sections of the ligula also do not show any nervous tissue inside (data not shown). Therefore a non-sensory function can be assigned to them.

\section{Labial Hairs}

Proximal to the labella, the outer surface of the labium is covered with scales, hairs and microtrichia (Figs. 1, 3, 37, 38). Pearson [12] using LM, found that the labial hairs of female $A$. aegypti are innervated. Using vital methylene blue staining, we found that there is one nerve cell associated with each hair with a nerve extending to the base of the hair,

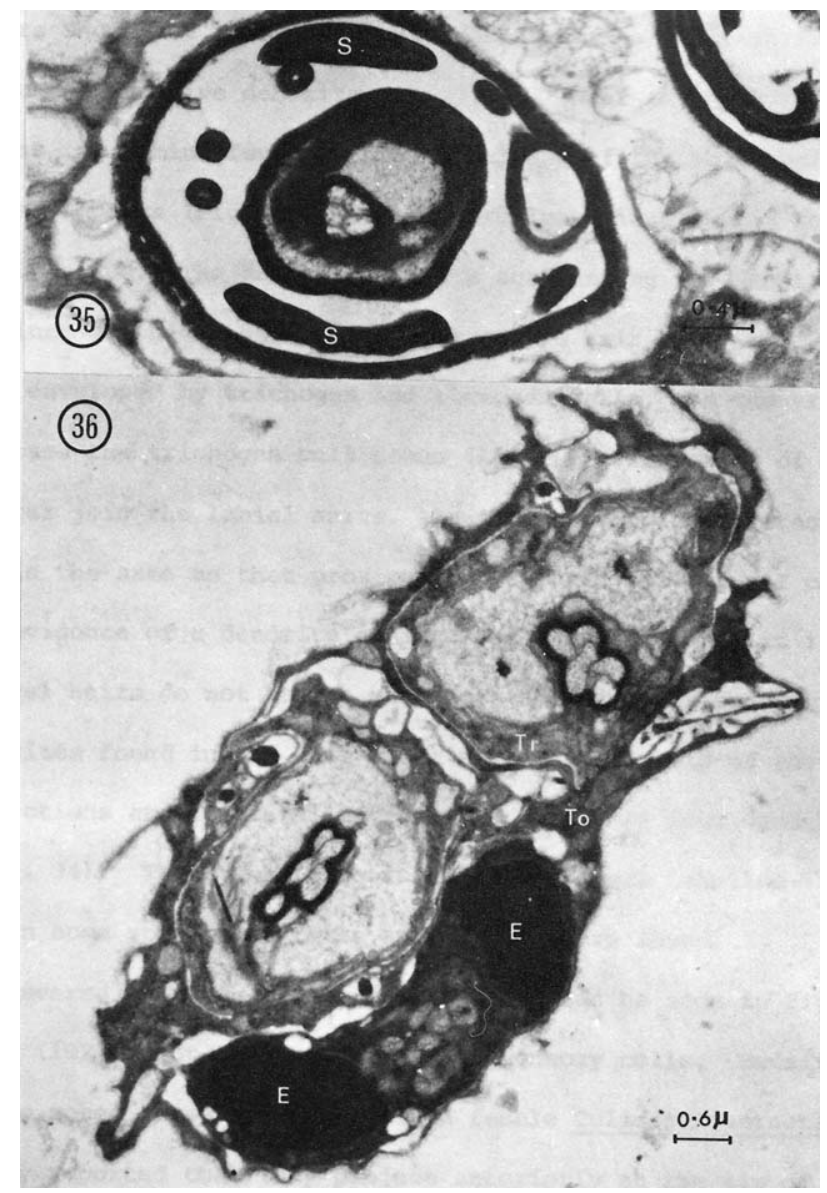

Fig. (35). Transverse section of an apical hair near the hair socket (S). A third lumen appears which is the extension of the trichogen cell sinus. Note five dendrites are found inside.

Fig. (36). Transverse section of two apical hair sensilla proximal to the hair base. Five dendrites are found inside the dendritic sheath enclosed by the trichogen cell (Tr). Two large vacuoles (E) filled with electron dense materials are associated with the tormogen cell (To).

suggesting that these hairs are probably mechanoreceptors. LM sections of the labium showed that these hairs have only a single lumen in the hair shaft (Fig. 37).

At the base of the labium, six to eight long socketed hairs are found on the ventral surface of the labium (Fig. 38). These hairs have sharp, pointed tips, with longitudinal grooves on the outer hair wall (Fig. 39), similar to the long labellar hairs. Whether these hairs are innervated has yet to be studied. However, their external morphology suggests that they are probably mechanoreceptors.

\section{DISCUSSION}

In the following, we will discuss the structure of the sensilla found on the labella and labium of $A$. aegypti in relation to previous reports; the probable functions of these receptors in the feeding behavior of mosquitoes are discussed based on the reports of other workers. 


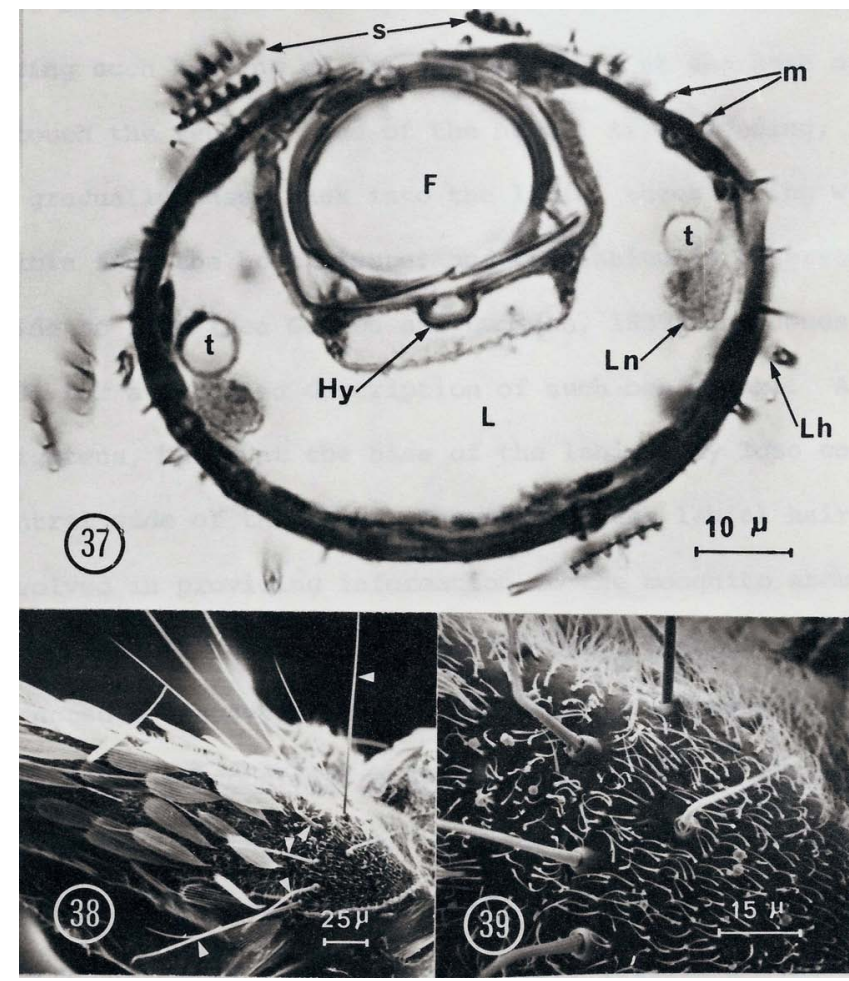

Fig. (37). Transverse section through the labium of a male $A$. aegypti showing the food canal (F) formed by the labrum. Hypopharynx (Hy) containing the salivary duct forms the ventral floor of the food canal. Two tracheal tubes $(\mathrm{t})$ with labial nerve $(\mathrm{Ln})$ close by are situated on the two lateral sides of the lumen (L). Long labellar hair (Lh), microtrichia (m) and scales (s) are found on the labial surface.

Fig. (38). Hairs (arrowheads) at the base of a labium from a male $A$. aegypti.

Fig. (39). Higher magnification of Fig. (38) showing socketed, longitudinally-grooved labial hairs among the microtrichia.

\section{STRUCTURE OF SENSILLA}

The labellar lobes of mosquitoes were considered by many workers as important in serving as a guide for the fascicle during piercing and sucking, but Robinson [27] found that mosquitoes with their labella removed were still able to feed on a host quite normally. Therefore he suggested that the labella serve to allow instant return of the stylets to the labial gutter after withdrawal, and that the theca of the labium is important in protecting the fascicle by conserving the fascicular fluid and preventing it from drying. Jones and Pilitt [28] however found that removal of the labella results in the failure of mosquitoes to penetrate the skin, thus showing the importance of the labella as a guide during piercing.

\section{Long Labellar Hairs}

Behavioral studies showed that long labellar hairs respond to mechanical stimulation [2]. But many workers [1, $3,4,11,13,15]$ have found only double-chambered hairs, and some of these workers have concluded that all aboral hairs beyond a certain length (e.g. $32 \mu \mathrm{m}$ in $C$. inornata as reported by Owen [3]) are chemosensory. Consequently be- havioral $[1,3,4,15]$ and electrophysiological studies [15, 19] were conducted on the long labellar hairs. However, Pearson [12] using electrophysiological methods found that long labellar hairs are very sensitive to minute mechanical deflections which normally result in proboscis extension. He also found that it is very difficult to apply a chemical to a long labellar hair without evoking a response from the mechanoreceptor, and cautioned the use of proboscis movement as the criterion for positive response towards chemical stimulation. Our morphological study supports his finding that the long 1abellar hairs are mechaoreceptors.

\section{Medium-Sized Hairs}

Chaika and Elizarov [13] reported one to five dendrites ascending into the lumen of the aboral chemosensory hairs in female A. aegypti. However, the reproduction of their micrographs was poor, and they did not show any sections of hair shafts containing less than three dendrites. Here we found 35 dendrites inside the medium-sized hairs of $A$. aegypti. In female $C$. inornata, Zwonitzer [11] using LM found three to four neurones associated with each aboral hair. Owen et al. [15] using TEM found two types of sensory hairs on the aboral surfaces of $C$. inornata: one containing three dendrites and the other with five dendrites proximal to the base of the hairs, but only four dendrites in the hair shaft.

Results from behavioral studies have indicated that mosquito labellar hairs are sensitive to water, sugar solutions and unacceptable compounds [1-4, 15-18]. Electrophysiological studies have also shown that these hairs are stimulated by water, sugar, and $\mathrm{NaCl}[5,15,19]$. Our study suggests that such responses may be mediated through the medium-sized hairs, which are double-chambered and innervated. However, many medium-sized hairs are located more proximally on the labellar lobes (Figs. 2, 3), and it is very likely that these hairs will never touch the substrate during probing and piercing. Mosquitoes often spread their labellar lobes when the labellar hairs are stimulated with sugar solutions [1-3, 14] and unacceptable compounds [18]. Such divarication will probably bring only some proximally-located hairs into contact with the substrate, thus raising an interesting question as to the probable function of the more proximally located medium-sized hairs.

Thick-walled chemoreceptors sensitive to strong odors have been reported on the labellar hairs of the stablefly Stomoxys calcitrans [29] and on the legs of grasshoppers [30]. Dethier [31] also found that chemoreceptors on the mouthparts and legs of the blowfly Phorinia regina that normally respond to aqueous solutions also respond to organic and inorganic acids, and various nonpolar compounds in gaseous state. It is possible that in mosquitoes, the more proximally located medium-sized hairs which do not normally come into contact with the substrate may respond to vapors.

The structure of the short papillae (Figs. 2-4) in A. aegypti has yet to be studied. In female $C$. inornata, Zwonitzer [11] using LM called these sensilla basiconica, but was uncertain about the number of neurones associated with each papilla. Because of their small size, it is unlikely that they will get in touch with the host surface during probing by the mosquito. They are probably olfactory receptors. Short microtrichia on the aboral surfaces are clearly not sensory. 


\section{Oral Papillae}

Vogel [10] had suggested that pseudotrachea on the oral surface of labella function in a manner similar to the suction cups on the toes of the gecko, by providing a strong hold on the skin of the host during biting and sucking. Robinson [27] pointed out that Vogel's suggestion has no backing. Still, Vogel was probably the first to notice the oral papillae in mosquitoes. He called them sensilla basiconica, and considered them to be shortened tactile bristles. Zwonitzer [11] found six of these papillae in female $C$. inornata, and also called them sensilla basiconica. Larsen and Owen [14] referred to these papillae as sensilla trichodea. Since these sense organs are papilla-like, and are present on the oral surfaces of the labella, we call them oral papillae in this study.

In C. inornata, Larsen and Owen [14] also found that the oral papillae are double-chambered. Their micrograph showed five dendrites enclosed in a dendritic sheath proximal to the base of the papilla. Pappas and Larsen [5] found 2-5 neurones associated with these papillae in $C$. inornata, but could not study their functions using electrophysiological method because of their small size and inaccessibility. In $A$. aegypti, we found 3-5 dendrites inside the big chamber of these papillae. If there is any mechanoreceptive dendrite associated with the oral papillae, such a dendrite instead of terminating near the base of the papilla probably enters the papillary lumen for a short distance (Fig. 28).

Larsen and Owen [14] found in C. inornata that when chemosensory hairs on the 1abella are placed in contact with water or sugar solution, the labellar lobes spread apart, thus permitting the ligula to come into contact with the test solution, causing the ligula to increase by $76.65 \%$ of its original size. Consequently the test solution will probably spread over the ligular surface and make contact with the oral papillae. They suggested that it is probably through this mechanism that the mosquito mediates sucking of water and sugar solution. Whether such a mechanism exists in A. aegypti remains to be investigated. In A. aegypti, the oral and ligular surfaces are very close to each other, leaving only a small space in between (see Fig. 10 of Lee, 1974)[32]. Solutions that come into contact with the tip of the labellar lobes can probably reach the oral papillae through capillary action.

\section{Chordotonal Organ}

This is the first report of chordotonal organs in the mosquito labellum. It is similar to the chordotonal organ described in the legs of the shore crab Carcinus maenas [33, 34], and also to the Johnston organ scolopidium of Drosophila melanogaster [35], in having two sensory cells associated with one chordotonal organ. However, in the mosquito, at the ciliary region of the sensory cells, the two cells are separated by cell membranes, whereas in the shore crab and fruitfly, the ciliary segments are inside the scolopale without any membrane separating them. Zacharuk and Blue [36] also found a chordotonal organ with a single nerve cell within the antennal cone of larval A. aegypti, and suggested that it functions either as a stretch receptor, or as a monitor for low frequency vibration in the adjacent aquatic environment.

Behavioral studies have shown that mosquitoes often spread their labella when the labellar hairs are stimulated with sugar, water, and unacceptable compounds, as dis- cussed above. But when mosquitoes are feeding on blood, the two labellar lobes are firmly held against each other [27, 28, 37]. Dr. W. Horsfall of the Department of Entomology, University of Illinois at Urbana, Illinois, U.S.A., had made a film on the feeding behavior of female A. aegypti feeding on the foot-web of a frog, and he kindly loaned us the film for study. We also noted that the two labellar lobes were closely held against each other during the whole process of feeding on the host. Chordotonal organs are generally recognized as stretch receptors. Whitear $[33,34]$ suggested that in chordotonal organs where each scolopidium is associated with two sensory cells, one sensory cell probably respond to stretching, and the other to slackening of the cap. The chordotonal organ in the mosquito labellum probably functions to monitor the spreading and closing of the labella during feeding. Both flexor and extensor muscles are present in the labella of mosquitoes [38].

\section{Apical Hairs}

To our knowledge, this is the first time that the presence and location of the apical hairs in the labella of mosquitoes has been documented. Transverse sections of the apical hairs can be seen in Figs. (5a and 6) of Vogel [10], but he labeled them as sensory cells. Zwonitzer [11] also noted these apical hairs in female $C$. inornata, but incorrectly reported that they project anteriorly at the tip of the labellum in the same plane as the oral papillae. Structurally, the apical hairs can be classified as thick-walled chemoreceptors. They differ from the medium-sized, aboral labellar hair in having a smooth outer wall. Since the apical hairs are so located that they will come into contact with the substrate when the mosquito is probing on the host, these hairs may be involved in the discrimination of the host.

\section{Ligular Hairs}

Owen [3] reported from his behavioural studies using $C$. inornata and Aedes dorsalis that ligular hairs are chemosensory and respond to water and sucrose. This was later refuted by Larsen and Owen [14], who found that the ligular hairs in. C. inornata are not chemosensory, and suggested that the behavioral response observed by Owen [3] was probably a result of the oral papillae coming into contact with the ligular surface which was coated with the test solution. Our results confirmed that the ligular hairs do not have a sensory function.

\section{Labial Hairs}

When a mosquito is feeding on a host, as the fascicle enters the host tissue, the labium becomes bent gradually, to a point where the labium almost becomes double under the head as the fascicle penetrates deeper. During such bending of the labium, hairs at the base of the labium may touch the ventral side of the head. After feeding, the fascicle is gradually eased back into the labial theca during withdrawal of the fascicle from the host tissue, and the labium is observed to rock from side to side [28, 37]. As the labium straightens, hairs at the base of the labium may lose contact with the ventral side of the head. Therefore these labial hairs are probably involved in providing information to the mosquito regarding the "state" of bending of the labium during and after feeding. Schiemenz [9] also noted a transverse row of seven hairs at the base of the labium in Culiseta annulata, and suggested 
that these hairs probably play a role as tactile hairs in the bending of the labium during piercing and sucking. Christophers [38] found in A. aegypti that the number and arrangement of these hairs are more regular in the females than in the males. This may be related to the blood-sucking behavior of the females, which involves bending of the labium during insertion of the fascicle and feeding, whereas such a behavior is absent in the male mosquitoes.

\section{Functions of Labellar and Labial Sensilla During Feed- ing}

From behavioural studies, mosquitoes are attracted by host odours, $\mathrm{CO}_{2}$, warmth, humidity, and optical stimuli. Detection of odours, $\mathrm{CO}_{2}$, warmth and chemo-attractants are the function of various receptors on the antennae of the mosquitoes [39-48]. Sensilla on the maxillary palps can also detect $\mathrm{CO}_{2}$ and mosquito repellents $[49,50]$. In nature, mosquitoes also feed on plant nectar, and such feeding affects the longevity and dispersal potential of mosquitoes [51]. In the following discussion, the probable chain of events regarding the feeding behaviour of mosquitoes after landing on a host is described based on the results from this study and the reports of other workers.

Mosquitoes often walk around soon after landing on a suitable host and probably detect the acceptability of the host using the chemoreceptors located on the tarsi of the pro- and mesothoracic legs. Tarsi of the metathoracic legs may not be important in host discrimination, as the hind legs are often raised when the mosquito is walking around. Behavioral studies have suggested that mosquito tarsal hairs are sensitive to sugar, salt and water [2-4]. Frings and Hamrum [2] found in A. aegypti that stimulation of the tarsal hairs with $\mathrm{NH}_{4} \mathrm{Cl}$ only made them restless, but the mosquito did not look for a more suitable substrate. Jones and Pilitt [28] found that when all the tarsi of female A. aegypti were removed, the mosquitoes were still able to pierce the skin and take a blood meal rapidly, indicating that the tarsi are not essential in providing the anchoring force for piercing.

Probing of the substrate using the two labellar lobes follows shortly after landing. The long labellar hairs probably monitor the positioning of the labellar lobes, with the medium-sized hairs near the labellar tip and the apical hairs detecting the suitability of the host. The medium-sized hairs posterior to the tip of the lobes probably detect the odour(s) from the host. When feeding on plant nectar, the presence of sugars may be detected by the labellar chemosensory hairs, so that the two lobes then spread apart, thus bringing the labral food canal opening to the solution [6]. The chordotonal organs in the labellar lobes may monitor the spreading and closing together of the lobes. The spreading of the labella also brings the ligula into contact with nectar, and this contact causes the ligula to increase in size. The function of this swelling of the ligula may be two fold. One is to spread the solution over the ligular surface, thus bringing the solution into contact with the oral papillae, thereby mediating the sucking of the solution, as suggested by Larsen and Owen [14]. The other is probably to hold the labral tip in place, and serve as a mechanical support, since the tip of the fascicle is situated in the dorsal groove of the ligula. Sucking activity of the cibarial and pharyngeal pumps is initiated when mediumsized hairs posterior to the tip of the labella and oral papillae are simultaneously stimulated [6]. During nectar feeding, the mosquito shows discontinuous suction [52, 53]. The food passing over the labral campaniform sensilla may affect the pumping action of both cibarial and pharyngeal pumps. The above description applies to both sexes of mosquitoes.

In female mosquitoes when feeding on blood, secretion present on the host skin, and also host odour probably stimulate the labellar chemosensory hairs. Now the labellar lobes do not spread apart, but are held tightly together. The penetration of the fascicle into the host tissue is aided by the alternating cutting action of the two maxillary stylets (laciniae) [27]. The overlapping mandibles probably cover the opening of the labrum during penetration, to prevent the host tissue from entering the food canal. Similarly, interdigitating finger-like projections at the tip of the hypopharynx may prevent possible blockage of the apical salivary canal opening by the tissue. Mandibular teeth are found in some species of mosquitoes [54], but the main function of the mandibles is to separate the food canal from the hypopharynx, to form a two-channel system: one for sucking the blood during feeding, and the other for the injection of saliva [32, 54].

During the initial insertion, the substance blocking the opening of the labral sense organs may get rubbed off by friction with the tissue, thus exposing the receptor sites. Lateral teeth on the two maxillary stylets (laciniae) are important in piercing and withdrawal of the fascicle during feeding, and these teeth are absent in mosquitoes which do not feed on blood [54]. The fascicle is very flexible in the host tissue, as it often bends dorsally at almost a right angle to the plane of insertion after entering the skin, and the tip of the fascicle is capable of bending in different directions [37]. Muscles controlling the two walls of the labrum are responsible for the dorsal and ventral flexion of the fascicle, and the differential actions of the laciniae are responsible for lateral flexion [55]. The apical and subapical sensilla probably detect the presence of blood $[18,32]$ and the stimulating factor in the blood is probably the adenine nucleotides $[16,56-58]$. Apical and subapical labral sensilla are absent in male mosquitoes which are not known to suck blood in nature, and in females of mosquitoes not known to suck blood [58]. Owen and Reinholz [59] found in C. inornata that water satiated mosquitoes refused 5-adenylic acid, ADP and ATP in Tris buffer, whereas thirsty mosquitoes imbibed these solutions. They therefore suggested that the acceptance of nucleotides was mediated by the water receptor.

As soon as a blood source is detected, the retractor muscles of the mandibles contract, exposing the opening of the food canal. Entry of food into the labral food canal may be detected by the labral campaniform sensilla, which may influence the action of the cibarial and pharyngeal pumps. The mosquito may feed by inserting the fascicle into a capillary (capillary feeding), or feed from the hemorrhage in the tissue caused by the puncture (pool feeding), with the average time for capillary feeding 3 minutes and 10 minutes for pool feeding $[37,60]$. Capillary feeding is more frequent than pool feeding [61]. Saliva is injected at different stages of penetration as tiny "puffs" [37], and such injection probably continues even after a blood supply is tapped [60], and saliva injection is an important step in the transmission of diseases carried by the mosquitoes. 
Palatal and dorsal papillae in the cibarium probably monitor the chemical nature of the food [62]. Indeed mosquitoes stop aspiration as soon as unacceptable compounds enter the cibarium $[3,18]$. If the food is blood, then the discontinuous suction is changed into continuous suction until the mosquito is satiated [3]. The trichoid sensilla probably register the flow of the food into the pump and the cibarial campaniform sensilla may monitor the pumping action of the cibarium [62]. The ventral papillae probably detect the type of food thus providing the information for the initiation of the switching mechanism: sugar solution enters the ventral diverticulum and blood goes to the midgut [62]. The two small dorsal diverticula probably function as air separators, trapping air that comes in with the food $[52,63]$. Sugar solution stored in the ventral diverticulum is gradually passed to the midgut for absorption [53]. Day [63] suggested that as a blood meal is required by a majority of female mosquitoes to mature their eggs, the ability to take a blood meal in spite of a recent nectar meal is of survival value. Another theory is that sugar solution in the diverticulum serves as a supply of water.

Termination of feeding is initiated by the intersegmental abdominal stretch receptors [64]. Withdrawal of the fascicle from the host tissue is aided by the laciniae, and Robinson [27] and Jones and Pilitt [28] had given detailed descriptions of this. The labellar lobes probably help the fascicle to return into the labial gutter after withdrawal [27].

\section{CONCLUSION}

Feeding behavior of mosquito is quite complex involving many types of receptors. Here we have provided a comprehensive description of the sense organs on the labella which are involved in host discrimination and initiation of feeding either on nectar or blood. Such knowledge is essential in our attempt to find more effective mosquito repellents in order to protect us from mosquito-borne diseases.

\section{ACKNOWLEDGEMENTS}

This study was supported by U.S. Army, Medical Research and Development Command Grant to the late Dr. B. Hocking, as well as National Research Council of Canada (NRC) and Natural Sciences and Engineering Research Council of Canada (NSERC) grants to DAC. We thank George Braybrook for his skillful operation of the scanning electron microscope.

\section{REFERENCES}

[1] Feir D, Lengy JI, Owen WB. Contact chemoreception in the mosquito Culiseta inornata (Williston): Sensitivity of the tarsi and labella to sucrose and glucose. J Insect Physiol 1961; 6: 13-20.

[2] Frings H, Hamrum CL. The contact chemoreceptors of adult yellow fever mosquitoes, Aedes aegypti. J N Y Entomol Soc 1950; 58 : $133-42$.

[3] Owen WB. The contact chemoreceptor organs of the mosquito and their function in feeding behaviour. J Insect Physiol 1963; 9: 73-87.

[4] Owen WB. Taste receptors of the mosquito Anopheles atroparvus van Thiel. J Med Entomol 1971; 8: 491-4.

[5] Pappas LG, Larsen JR. Gustatory hairs on the mosquito, Culiseta inornata. J Exp Zool 1976; 196: 351-60.

[6] Pappas LG, Larsen JR. Gustatory mechanisms and sugar feeding in the mosquito Culiseta inornata. Physiol Ent 1978; 3: 115-20.

[7] Clements AN. The physiology of mosquitoes. London: Pergamon Press 1963.
Nuttall GHF, Shipley AE. Studies in relation to malaria II: the structure and biology of Anopheles (Anopheles maculipennis). J Hyg 1901; 1: 451-483.

[9] Schiemenz II. Vergleichende funktionell-anatomische untersuchungen der lopfmuskulatur von Theobaldia und Eristalis (Dipt. Culicid. und Syrphid.). Deutsche Ent Zeitschr - N F 1957; 5: 268331.

[10] Vogel R. Kristische und erganzende Mitteilungen zur Anatomie des Stechapparats der Culiciden und Tabaniden. Zool J (Abt Anat ) 1921; 42: 259-82.

[11] Zwonitzer RL. The morphology and histology of the labellar contact chemoreceptors of the female mosquito Culiseta inornata (Williston). M.Sc. thesis, University of Wyoming 1962.

[12] Pearson TR. The structure and function of the apical labral pegs and long labellar hairs of the mosquito Aedes aegypti (L.). Ph. D. thesis, University of Alberta 1970.

[13] Chaika SY, Elizarov YA. Electron microscopic investigation of the labellar trichoid sensilla of mosquito Aedes aegypti L. Contribution to the lst All-Union Symposium on insect chemoreception. Meeting Proceeding 1971; 67-73.

[14] Larsen JR, Owen WB. Structure and function of the ligula of the mosquito Culiseta inornata (Williston). Trans Am Microsc Soc 1971; 90: 294-308.

[15] Owen WB, Larsen JR, Pappas LG. Functional units in the labellar chemosensory hairs of the mosquito Culiseta inornata (Williston). J Exp Zool 1974; 188: 235-48.

[16] Hosoi T. Mechanism enabling the mosquito to ingest blood into the stomach and sugary fluids into the oesophageal diverticula. Annot Zool Jpn 1954; 27: 82-90.

[17] Owen WB. Behavioural studies of inhibition and integration in the mosquito Culiseta inornata (Williston). J Exp Zool 1967; 166: 3016.

[18] Salama HS. The function of mosquito taste receptors. J Insect Physiol 1966; 12: 1051-60.

[19] Zwonitzer RL. An electrophysiological study of the labellar contact chemoreceptors of the female mosquito Culiseta inornata (Williston). Ph. D. thesis, University of Wyoming 1969.

[20] Burgess L, Remple JG. The stomodaeal nervous system, the neurosecretory system, and the gland complex in Aedes aegypti (L.)(Diptera: Culicidae). Can J Zool 1966; 44: 731-65.

[21] Hooper RL, Pitts CW, Westfall JA. Sense organs on the ovipositor of the face fly, Musca autumnalis. Ann Entomol Soc Am 1972; 65: 577-586.

[22] Slifer EH. A rapid and sensitive method for identifying permeable areas in the body wall of insects. Entomol News 1960; 71: 179-82.

[23] Slifer EH, Sekhon SS. The fine structure of the sense organs on the antennal flagellum of the yellow-fever mosquito Aedes aegypti (L.). J Morph 1962; 111: 49-68.

[24] Sturckow B, Holbert PE, Adams JR. Fine structure of the tip of chemosensitive hairs in two blow flies and the stable fly. Experientia 1967; 23: 780-2.

[25] Sturckow B, Holbert PE, Adams JR, Anstead RJ. Fine structure of the tip of the labellar taste hair of the blow flies, Phormia regina (Meg.) and Calliphora vicina R.-D (Diptera, Calliphoridae). Z Morph Tiere 1973; 75: 87-109.

[26] Slifer EH. The structure of arthropod chemoreceptors. Annu Rev Entomol 1970; 15: 121-42

[27] Robinson GG. The mouthparts and their function in the female mosquito, Anopheles maculipennis. Parasitology 1939; 31: 212-42.

[28] Jones JC, Pilitt DR. Blood-feeding behaviour of adult Aedes aegypti mosquitoes. Biol Bull 1973; 145: 127-39.

[29] Hopkins BA. The probing response of Stomoxys calcitrans (L.)(the stable fly) to vapours. Anim Behav 1964; 12: 513-24.

[30] Slifer EH. The reaction of a grasshoper to an odorous material held near one of its feet (Orthoptera: Acrididae). Proc R Entomol Soc Lond Ser A 1954; 29: 177-9.

[31] Dethier VG. Sensitivity of the contact chemoreceptors of the blowfly to vapors. Proc Natl Acad Sci USA 1972; 69: 2189-92.

[32] Lee R. Structure and function of the fascicular stylets, and the labral and cibarial sense organs of male and female Aedes aegypti (L.)(Diptera, Culicidae). Quaest Entomol 1974; 10: 187-215.

[33] Whitear M. Chordotonal organs in Crustacea. Nature 1960; 187: 522-3.

[34] Whitear M. The fine structure of crustacean proprioceptors I. The chordotonal organs in the legs of the shore crab, Carcinus maenas. Philos Trans R Soc Lond B 1962; 245: 291-324. 
[35] Uga S, Kuwabara M. On the fine structure of the chordotonal sensillum in antenna of Drosophila melanogaster. J Electron Microsc (Tokyo) 1965; 14: 173-81.

[36] Zacharuk RY, Blue SG. Ultrastructure of a chordotonal and a sinusoidal peg organ in the antenna of larval Aedes aegypti (L.). Can J Zool 1971; 49: 1223-9.

[37] Gordon RM, Lumsden WHR. A study of the behaviour of the mouth-parts of mosquitoes when taking up blood from living tissue; together with some observations on the ingestion of microfilariae. Ann Trop Med Parasitol 1939; 33: 259-78.

[38] Christophers SR. Aedes aegypti (L.), the yellow fever mosquito: its life history, bionomics and structure. London: Cambridge University Press 1960.

[39] Ghaninia M, Ignell R, Hansson BS. Functional classification and central nervous projections of olfactory receptor neurons housed in antennal trichoid sensilla of female yellow fever mosquitoes, Aedes aegypti. Eur J Neurosci 2007; 26(6): 1611-23.

[40] Grant AJ, O'Connell RJ. Age-related changes in female mosquito carbon dioxide detection. J Med Entomol 2007; 44(4): 617-23.

[41] Qiu YT, van Loon JJ, Takken W, Meijerink J, Smid HM. Olfactory coding in antennal neurons of the malaria mosquito, Anopheles gambiae. Chem Senses 2006; 31: 845-63.

[42] Pitts RJ, Zwiebel LJ. Antennal sensilla of two female anopheline sibling species with differing host ranges. Malaria J 2006; 5: 26.

[43] Gingl E, Hinterwirth A, Tichy H. Sensory representation of temperature in mosquito warm and cold cells. J Neurophysiol 2005; 94: $176-85$.

[44] Meijerink J, van Loon JJ. Sensitivities of antennal olfactory neurons of the malaria mosquito, Anopheles gambiae, to carboxylic acids. J Insect Physiol 1999; 45: 365-73.

[45] Meijerink J, Braks MA, van Loon JJ. Olfactory receptors on the antennae of the malaria mosquito Anopheles gambiae are sensitive to ammonia and other sweat-borne components. J Insect Physiol 2001; 47(4-5): 455-64.

[46] Takken W. Synthesis and future challenges: the response of mosquitoes to host odours. Ciba Found Symp 1996; 200: 302-12.

[47] Bowen MF. Sensory aspects of host location in mosquitoes. Ciba Found Symp 1996; 200: 197-208.

[48] Sutcliffe JF. Sensory bases of attractancy: morphology of mosquito olfactory sensilla-- a review. J Am Mosq Control Assoc 1994; 10(2 Pt 2): 309-15.

[49] Syed Z, Leal WS. Maxillary palps are broad spectrum odorant detectors in Culex quinquefasciatus. Chem Senses 2007; 32: 72738.
[50] Amer A, Mehlhorn H. The sensilla of Aedes and Anopheles mosquitoes and their importance in repellency. Parasitol Res 2006; 99: 491-9.

[51] van Handel E. The detection of nectar in mosquitoes. Mosq News 1972; 32: 458

[52] McGregor ME. The artificial feeding of mosquitoes by a new method which demonstrates certain function of the diverticula. Trans R Soc Trop Med Hyg 1930; 23: 329-31.

[53] McGregor ME. The nutrition of adult mosquitoes: prelimiinary contribution. Trans R Soc Trop Med Hyg 1931; 24: 465-72.

[54] Lee RMKW, Craig DA. Maxillary, mandibulary, and hypopharyngeal stylets of female mosquitoes (Diptera: Culicidae); a scanning electron microscope study. Can Entomol 1983; 115: 1503-12.

[55] Waldbauer GP. The mouth parts of female Psophora ciliata (Diptera, Culicidae) with a new interpretation of the functions of the labral muscles. J Morph 1962; 111: 201-15.

[56] Werner-Reiss U, Galun R, Crnjar R, Liscia A. Factors modulating the blood feeding behavior and the electrophysiological responses of labral apical chemoreceptors to adenine nucleotides in the mosquito Aedes aegypti (Culicidae). J Insect Physiol 1999; 45: 801808.

[57] Werner-Reiss U, Galun R, Crnjar R, Liscia A. Sensitivity of the mosquito Aedes aegypti (Culicidae) labral apical chemoreceptors to phagostimulants. J Insect Physiol 1999; 45: 629-36.

[58] Lee RMKW, Craig DA. The labrum and labral sensilla of mosquitoes (Diptera: Culicidae): A scanning electron microscope study Can J Zool 1983; 61: 1568-79.

[59] Owen WB, Reinholz S. Intake of nucleotides by the mosquito Culiseta inornata in comparison with water, sucrose, and blood. Exp Parasitol 1968; 22: 43-9.

[60] Griffiths RB, Gordon RM. An apparatus which enables the process of feeding by mosquitoes to be observed in the tissue of a live rodent; together with an account of the ejection of saliva and its significance in malaria. Ann Trop Med Parasitol 1952; 46: 311-9.

[61] O'Rourke FJ. Observations on pool and capillary feeding in Aedes aegypti (L.). Nature 1956; 177: 1087-8.

[62] Lee RMKW, Craig DA. Cibarial sensilla and armature in mosquito adults (Diptera: Culicidae). Can J Zool 1983; 61: 633-46.

[63] Day MF. The mechanism of food distribution to midgut or diverticula in the mosquito. Aust J Biol Sci 1954; 7: 515-24.

[64] Gwardz RW. Regulation of blood meal size in the mosquito. J Insect Physiol 1969; 15: 2039-2044.

(c) Lee and Craig et al.; Licensee Bentham Open.

This is an open access article licensed under the terms of the Creative Commons Attribution Non-Commercial License (http://creativecommons.org/licenses/by-nc/3.0/) which permits unrestricted, non-commercial use, distribution and reproduction in any medium, provided the work is properly cited. 